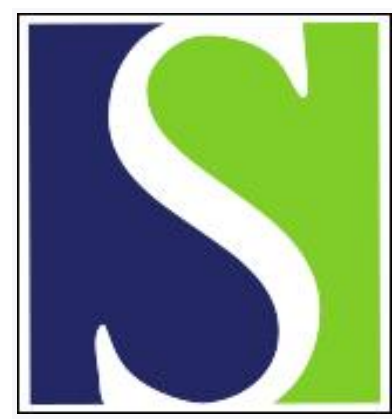

Scand J Work Environ Health 2019;45(3):256-266

https://doi.org/10.5271/sjweh.3788

Published online: 26 Nov 2018, Issue date: 01 May 2019

Night and rotational work exposure within the last 12 months and risk of incident hypertension

by Ferguson JM, Costello S, Neophytou AM, Balmes JR, Bradshaw PT, Cullen MR, Eisen EA

Prior research has been unable to disentangle the impact of shift type (eg, night work) or rotations (ie, switching from day to night), as a driver of increased hypertension risk. In this study, we observed an increased hypertension risk among recent night and rotational workers. Furthermore, recent night and rotational work may be independently associated with higher rates of hypertension.

Affiliation: Division of Environmental Health Sciences, School of Public Health, University of California, Berkeley, Berkeley, CA 94720-7360 USA. jackie.ferguson@berkeley.edu

Refers to the following texts of the Journal: 2015;41(3):268-279 1999;25(2):100-104 2004;30(2):149-156

The following articles refer to this text: 2019;45(5):465-474; 2020;46(6):557-569; 2022;48(1):31-40

Key terms: exposure; hypertension; incident hypertension; longitudinal; night work; occupational health; occupational health; rotational work; shift rotation; shift work; shift worker; time-registry; working time

This article in PubMed: www.ncbi.nlm.nih.gov/pubmed/30614503

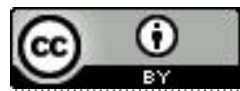




\title{
Night and rotational work exposure within the last 12 months and risk of incident hypertension
}

\author{
by Jacqueline M Ferguson, MHS, ${ }^{1}$ Sadie Costello, PhD, ${ }^{1}$ Andreas M Neophytou, ScD, ${ }^{1}$ John R Balmes, MD, ${ }^{1}$ Patrick T \\ Bradshaw, PhD, ${ }^{2}$ Mark R Cullen, MD, ${ }^{3}$ Ellen A Eisen, $S c D^{1}$
}

\begin{abstract}
Ferguson JM, Costello S, Neophytou AM, Balmes JR, Bradshaw PT, Cullen MR, Eisen EA. Night and rotational work exposure within the last 12 months and risk of incident hypertension. Scand J Work Environ Health. 2019;45(3):256-266. doi:10.5271/ sjweh.3788
\end{abstract}

\begin{abstract}
Objectives Shift work, such as alternating day and nights, causes chronobiologic disruptions which may cause an increase in hypertension risk. However, the relative contributions of the components of shift work - such as shift type (eg, night work) and rotations (ie, switching of shift times; day to night) - on this association are not clear. To address this question, we constructed novel definitions of night work and rotational work and assessed their associations with risk of incident hypertension.
\end{abstract}

Methods A cohort of 2151 workers at eight aluminum manufacturing facilities previously studied for cardiovascular disease was followed from 2003 through 2013 for incident hypertension, as defined by ICD-9 insurance claims codes. Detailed time-registry data was used to classify each worker's history of rotational and night work. The associations between recent rotational work and night work in the last 12 months and incident hypertension were estimated using adjusted Cox proportional hazards models.

Results Elevated hazard ratios (HR) were observed for all levels of recent night work $(>0-5,>5-50,>50-95$, $>95-100 \%)$ compared with non-night workers, and among all levels of rotational work $(<1,1-10,>10-20$, $>20-30$, and $>30 \%$ ) compared with those working $<1 \%$ rotational work. In models for considering the combination of night and rotational work, workers with mostly night work and frequent rotations $(\geq 50 \%$ night and $\geq 10 \%$ rotation) had the highest risk of hypertension compared to non-night workers [HR $4.00,95 \%$ confidence interval (CI )1.69-9.52].

Conclusions Our results suggest recent night and rotational work may both be associated with higher rates of incident hypertension.

Key terms longitudinal; night work; occupational health; shift rotation; shift work; shift worker; time-registry; working time.

Shift work is often attractive to workers due to flexible schedules and increased wages. However, these benefits may come at a cost to workers' health. Shift work has been associated with hypertension, a risk factor for cardiovascular disease (1-4). Yet, prior research has been unable to disentangle the relative importance of particular shift patterns as the drivers for increased risk. Workplaces have utilized shift work for decades to arrange successive work shifts such that they may operate longer hours $(5,6)$. As a result, there are many different and highly customized work schedules that are considered shift work. Definitions in the literature include rotating shifts, weekend work, and various shift schedules that may or may not include night work $(1,7)$. Although there are no uniform definitions that encompass all variants of shift work, estimates of the prevalence of shift work range up to nearly $20 \%$ in the US workforce $(5,8)$. Prior research indicates that two primary components of shift work may be relevant to the risk of hypertension, type of shift defined by the time of work (eg, day versus night work) and the rotation of shifts (ie, switching scheduled shift times), both of which have the potential to disrupt circadian rhythms (1, 7). Imbalance in circadian rhythms may compromise the ability of organ systems, including the cardiovascular system, to adapt to external stimuli $(7,9-12)$. However,

1 Division of Environmental Health Sciences, School of Public Health, University of California, Berkeley, California, USA

2 Division of Epidemiology and Biostatistics, School of Public Health, University of California, Berkeley, California, USA.

3 Department of Internal Medicine, Stanford School of Medicine, Stanford University, Stanford, California, USA

Correspondence to: Jacqueline M Ferguson, Division of Environmental Health Sciences, School of Public Health, University of California, Berkeley, Berkeley, CA 94720-7360 USA.[E-mail:jackie.ferguson@berkeley.edu] 
few studies have been able to assess the effects of shift type and rotations on hypertension risk separately and simultaneously in the same cohort (1). Furthermore, there is ambiguity regarding the biologically relevant time period in which hypertension develops following exposure to shift work (4). While human-based laboratory studies have identified that circadian misalignment causes alteration in the diurnal variation of blood pressure within 24 hours of shift work (13), epidemiological studies examining recent exposure to shift work are conflicting and examine exposure periods that vary in length from 1-20 years $(3,14)$. We hypothesize that shift work in the previous year may be an important time window of exposure for the development of hypertension given the acute impacts shift work can have on blood pressure. To explore the impact of recent night and rotational work on hypertension, we examined novel exposure metrics of rotations and night work in a study of incident hypertension using objective time-registry data in a cohort study of US aluminum manufacturing workers. Additionally, we examined the associations between hypertension and the combinations of night work and rotational work.

\section{Methods}

\section{Study population}

The study population is part of the American Manufacturing Cohort (AMC), comprising hourly employees at light-metal smelter, refinery, and fabricating facilities operating 24 hours a day in the United States. Workers performed blue-collar work (ie, jobs requiring manual labor; not including secretarial or office work) and included tasks such as anode assembly operator, sheet finishing, pack/ship operator, casting, autoclaving, and electrical or mechanical maintenance (15). Detailed information on employee demographics, work environments, and health were obtained from employment records, company personnel files, industrial hygiene records, and insurance claims.

In total, 3790 hourly workers in eight facilities employed in shift work were potentially eligible for study inclusion. These workers had shift work exposure data recorded within 10 days of hire and were hired after 2003 when shift work data became available. Workers were excluded if they were employed for less than one year (1251 workers), or non-concurrently enrolled in the insurance plan (125 workers). In addition, 263 workers with prevalent hypertension, as determined from claims in the first year of employment, were excluded. Our final analytic dataset comprised 2151 hourly workers without diagnosed prevalent hypertension. Follow-up times were censored on the date workers switched insurance plans, left employment with the company, or were otherwise lost to follow-up. Follow-up times were also censored at the first instance of missing shift work data if it was missing for more than two weeks.

\section{Night work and rotational work exposure}

Exposure assessment for night work and rotational work was based on daily working hour data retrieved from two time-registry systems used to calculate payroll from 27 December 2002 through the end of 2013. Each exposure metric was calculated from an individual's first active working date until either the date of hypertension diagnosis, administrative censoring, or the end of the follow-up period, 31 December 2013, whichever came first. Non-work hours (eg, sick leave, vacation) and shifts $<3$ hours $(<0.5 \%)$ were defined as non-exposed person-time. Additionally, any shifts $>18$ hours $(<0.1 \%$ of all shifts) were excluded as potential exposures as they likely represented paid time during which employees were allowed to sleep. Shifts with $\leq 30$ minutes unpaid time (eg, meal breaks) between them were considered one continuous shift. Night shifts were classified using starting time and duration according to the most commonly employed definition of night work in time register studies work by Härmä et al (16) and Garde et al (17): a night shift is a shift with $\geq 3$ hours between 23:00-06:00 hours. Shifts not defined as night shifts were considered non-night shifts. Recent night work exposure was defined as the mean monthly percentage of shifts that were night shifts over the previous 12 months (ie, the number of night shifts per month/total number of shifts per month in a moving window average of 12 months).

Among this population of shift workers, there was exceptional variety in the shift systems used with multiple rotation schedules and shift lengths (eg, 12-hour night shifts for 4 days, 2/3/4 weeks alternating 8-hour shifts at different start times, permanent 8 -hour shifts, etc.). Therefore, rotational shifts were defined to objectively identify a switch to a different shift based on start time rather than by classification of the shift plans. The plants generally operated with either three 8-hour shifts per day or two 12-hour shifts per day, or a combination of both operating independently to ensure 24-hour operation. A minimum 6-hour absolute value displacement in start time was chosen to identify a shift with schedule rotation as most plants had $\geq 8$ hours between each shift start. We chose 6 hours to avoid capturing when a worker arrives early or late for their scheduled shift and to capture a true shift change (ie, morning to night rotation). For example, a shift at 11:00 hours followed by a shift the next day at 07:00 hours would not be categorized as a shift rotation because the absolute 
value of the shift start time displacement was 4 hours (ie, 11-7=4). In comparison, a shift at 16:00 hours followed by a shift the next day at 23:00 hours would be categorized as a rotation because the absolute value of the shift start time displacement was 7 hours. Shifts on the same day were not classified as rotations to avoid identifying a rotation for a shift with breaks $>30$ minutes (ie, long lunch break). Shifts that both began on the same calendar day were rare $(<1 \%)$. Recent rotational work exposure was defined similarly to night work: the mean monthly percent of shifts that had rotations over the past 12 months.

Night and rotational work occurring $>12$ months prior to the index date were considered "historical exposures" and defined in the same manner; the mean monthly percentage of night and rotational shifts, respectively, from the beginning of follow-up until the beginning of the previous year.

\section{Hypertension outcome}

Incident hypertension was defined as a face-to-face (outpatient or hospitalization) diagnosis (ICD 9: 401.x-405.x) identified from medical insurance claims, similar to previous analyses (18-22). Anti-hypertension medications were not part of the case definition since they are prescribed for multiple indications beyond treatment of hypertension (23). If a face-to-face claim for hypertension occurred within the first year of follow up, the worker was considered to have prevalent hypertension and was excluded from analysis (ie, a one-year washout period for prevalent hypertension).

\section{Covariates}

Baseline sex, age, and race, as well as time-varying job grade and plant location were obtained through human resource records. Race was categorized as white/Asian, Hispanic, black, and other (multi-racial and Native American/Alaska native). Job grade, a classification matrix for jobs based on experience, skill level, seniority and prestige, ranged from 2-49 (24) and was dichotomized into low and high job grade based on the facility-specific median job grade. Job grade was considered an a priori confounder because jobs with higher seniority may result in more realized preference in schedule selection, and job grade is correlated with wages which are strong predictors of health (24). Time-varying body mass index (BMI) and smoking status were obtained through Occupation Health and Safety Administration (OSHA) mandated examinations such as respirator fit tests. These clinic records were maintained only for active workers resulting in missing data for BMI and smoking. BMI was classified into underweight, normal weight, overweight, and obese according to the Centers for Disease Control
(CDC) standard definitions: underweight $<18.5 \mathrm{~kg} / \mathrm{m}^{2}$, Normal $18.5-24.9 \mathrm{~kg} / \mathrm{m}^{2}$, overweight $25.0-29.9 \mathrm{~kg} / \mathrm{m}^{2}$, and obese $\geq 30.0 \mathrm{~kg} / \mathrm{m}^{2}(25)$. Smoking status was categorized into never, current, and ever (ex-smoker). Insurance records also provide a "risk score", an insurance predictive health expenditures metric, used in this analysis as a surrogate for time-varying health status $(19,26,27)$. These annual scores were originally developed to predict an individual's health expenditures in the coming year and are standardized such that a score of 1 indicates the individual's health expenditures are likely to fall at the mean. Each one unit increase predicts a one-fold increase in expenditures above the mean (26).

\section{Statistical analysis}

We fit three separate Cox proportional hazard models with attained age as the time scale to estimate hazard ratios (HR) for developing hypertension as a function of: (i) night work, (ii) rotational work, and (iii) combinations of both night and rotational work. Baseline hazards for all models contained a strata statement for sex and location to meet the proportional hazards assumptions (28). We verified that the proportional hazard assumption was met using Schoenfeld residuals for each model. Models were additionally adjusted for race, plant location, job grade, risk score, and calendar year. History of night work was adjusted for when examining associations with recent night work, and history of rotational work was adjusted for when examining recent rotational work.

Categories of recent and historical night work exposure were defined a priori to identify those workers with no night work exposure (ie, non-night workers only), those with very little night work exposure, and workers with near permanent night work. The midrange exposures were divided equally. The categories of recent night work exposure were $0 \%$ (ie, non-night work only), $>0-5 \%$ (ie, those with very little night work exposure), $5-<50,50-95$, and $>95-100 \%$ night shifts (ie, near permanent night workers). Historical night work exposure was modeled as a continuous variable, using restricted cubic splines (29).

Rotational work exposure categories were designated a priori to identify unexposed workers. However, due to the small number of workers who were unexposed to rotations over an entire year, the reference category was modified to include those with $<1 \%$ rotational shifts. The remaining exposures were then classified by decile (eg, $0-<1,1-10,>10-20,>30 \%$ ). Historical rotational work exposure was modeled using restricted cubic splines (29). Tests for trend were performed for exposure based on the mean percentage of each night/ rotational work category.

To examine the association between combinations of night and rotational work on the risk of hypertension, the 
exposure categories were combined using the quadrant method a-priori into: non-night workers with infrequent rotations ( $0 \%$ night work and $<10 \%$ rotations), nonnight workers with frequent-rotations $(0 \%$ night work and $\geq 10 \%$ rotations), mostly non-night workers with infrequent rotations $(<50 \%$ night work and $<10 \%$ rotations), mostly non-night workers with frequent rotations ( $<50 \%$ and $\geq 10 \%$ rotations) mostly night workers with infrequent rotations ( $\geq 50 \%$ night work and $<10 \%$ rotations), and mostly night workers with frequent rotations ( $\geq 50 \%$ night work and $\geq 10 \%$ rotations). However, due to small numbers of non-night workers, the two categories of non-night workers were combined to non-night workers ( $0 \%$ night work) regardless of rotations.

We did not control for BMI or smoking in the primary analyses since these variables may be on the causal pathway from night work to hypertension (30-33). In a sensitivity analysis, we assumed a different causal structure and treated smoking and BMI as confounders. Missing values for smoking status (60\% missing) and BMI (30\% missing) were imputed using multivariable imputation by chained equations (MICE) in 60 simulated datasets, equal to the percentage of missing smoking data $(28,34-36)$.

Several sensitivity analyses were performed to assess the robustness of the main results. First, we implemented two alternate classifications of night work: (i) any night shifts versus none, and (ii) number of months working any night shifts. Second, we explored an alternate definition of night shifts using the International Agency for Research on Cancer (IARC) 2007 report: a night shift is a shift with $\geq 3$ hours between 0:00-05:00 hours (5). Third, we restricted analysis to workers with $\geq 150$ shifts per year.

All statistical analyses were performed in Stata version 15, 2017 (StataCorp LLC, College Station, TX, USA). The Institutional Review Board at the University of California, Berkeley, approved this study (Protocol ID: 2010-07-1823).

\section{Results}

Among the 2151 shift workers, 215 incident cases of hypertension were observed over 5231 person-years. Follow-up time ranged from 1 month to almost 10 years, with a mean of 2.5 years. Table 1 presents baseline characteristics of the cohort and the average percent of recent night and rotational work for each covariate category. The cohort was mostly white male with an average age of 37 years at baseline. The average risk score of 0.49 indicated that, on average, workers were predicted to have health expenditures below the mean of a nationally representative population in the coming year (26). The percentage of recent night work at baseline was higher among hypertensive cases, women, multi-racial workers and those with a lower job grade. Percentage of recent rotational work at baseline was higher among non-cases, men, and lower job grades.

As seen in figure 1, the eight plants operated on either a two-shift, three-shift, or a combination of two- and three-shift system. Plants 1, 2, and 3 all had a two-shift system, consisting of a morning shift starting around 06:00 hours and a night shift starting around 18:00 hours. Plants 4, 5, and 6 operated on a three-shift system: a morning, afternoon, and night shift. While plants 7 and 8 operated on a combination of two- and three-shift systems that consisted of a morning, early afternoon, evening, and night shift. There was also some variability in the shift

Table 1. Baseline characteristics of the American Manufacturing Cohort (AMC), eight plant sub-cohort 2003-2013, USA, at cohort entry ( $\mathrm{N}=2151$ ).

\begin{tabular}{|c|c|c|c|c|}
\hline & $\mathrm{N}$ & $\%$ & $\begin{array}{l}\text { Average \% } \\
\text { recent night } \\
\text { work }^{a}\end{array}$ & $\begin{array}{l}\text { Average \% } \\
\text { recent rota- } \\
\text { tional work }\end{array}$ \\
\hline \multicolumn{5}{|l|}{ Hypertension cases/ } \\
\hline \multicolumn{5}{|l|}{ Non-cases } \\
\hline Cases & 215 & 10 & 58.2 & 8.6 \\
\hline Non-cases & 1936 & 90 & 32.9 & 15.0 \\
\hline \multicolumn{5}{|l|}{ Sex } \\
\hline Male & 1963 & 91 & 32.3 & 15.3 \\
\hline Female & 193 & 9 & 39.8 & 12.1 \\
\hline \multicolumn{5}{|l|}{ Race } \\
\hline White (not Hispanic or Latino) & 1601 & 74.5 & 34.5 & 15.7 \\
\hline Hispanic or Latino & 266 & 12.3 & 27.6 & 12.2 \\
\hline $\begin{array}{l}\text { Black or African American } \\
\text { (not Hispanic or Latino) }\end{array}$ & 233 & 10.8 & 28.2 & 13.3 \\
\hline $\begin{array}{l}\text { American Indian or } \\
\text { Alaska native }\end{array}$ & 23 & 1.1 & 30.4 & 16.2 \\
\hline $\begin{array}{l}\text { Asian/native Hawaiian/ } \\
\text { other Pacific Islander }\end{array}$ & 17 & 0.8 & 29.4 & 11.3 \\
\hline $\begin{array}{l}\text { Multi-racial (not Hispanic } \\
\text { or Latino) }\end{array}$ & 11 & 0.5 & 45.7 & 19.0 \\
\hline \multicolumn{5}{|l|}{ Smoking status } \\
\hline Never & 327 & 15 & 36.4 & 15.4 \\
\hline Current & 144 & 7 & 36.9 & 17.5 \\
\hline Ever & 364 & 17 & 28.8 & 17.6 \\
\hline Missing & 1316 & 61 & 32.7 & 13.9 \\
\hline \multicolumn{5}{|l|}{ Body mass index $\left(\mathrm{kg} / \mathrm{m}^{2}\right)$} \\
\hline Underweight (<18.5) & 6 & 0.3 & 43.9 & 23.9 \\
\hline Normal (18.5-24.9) & 296 & 13.5 & 36.1 & 17.6 \\
\hline Overweight (25.0-29.9) & 577 & 26.8 & 33.0 & 16.2 \\
\hline Obese $(\geq 30.0)$ & 626 & 29.6 & 33.3 & 15.7 \\
\hline Missing & 642 & 29.9 & 31.0 & 11.9 \\
\hline \multicolumn{5}{|l|}{ Job grade by facility } \\
\hline Lower job grade & 959 & 44.6 & 34.6 & 16.2 \\
\hline Upper job grade & 1192 & 55.4 & 28.9 & 12.2 \\
\hline \multicolumn{5}{|l|}{ Age (years) } \\
\hline$<25$ & 358 & 16.6 & 30.4 & 14.9 \\
\hline$\geq 25-30$ & 501 & 23.3 & 33.2 & 16.9 \\
\hline$\geq 30-40$ & 728 & 33.8 & 34.4 & 15.8 \\
\hline$\geq 40-50$ & 398 & 18.5 & 32.9 & 13.3 \\
\hline$\geq 50$ & 166 & 7.7 & 31.2 & 10.2 \\
\hline \multicolumn{5}{|l|}{$\begin{array}{l}\text { Risk score (health status mea- } \\
\text { sure) quartiles }\end{array}$} \\
\hline$<0.31$ & 510 & 510 & 34.4 & 15.6 \\
\hline$\geq 0.31-0.49$ & 571 & 571 & 33.2 & 16.6 \\
\hline$\geq 0.49-0.78$ & 537 & 537 & 32.6 & 14.7 \\
\hline$\geq 0.78$ & 533 & 533 & 31.6 & 13.0 \\
\hline
\end{tabular}

a Exposure in prior 1 year to follow-up. 


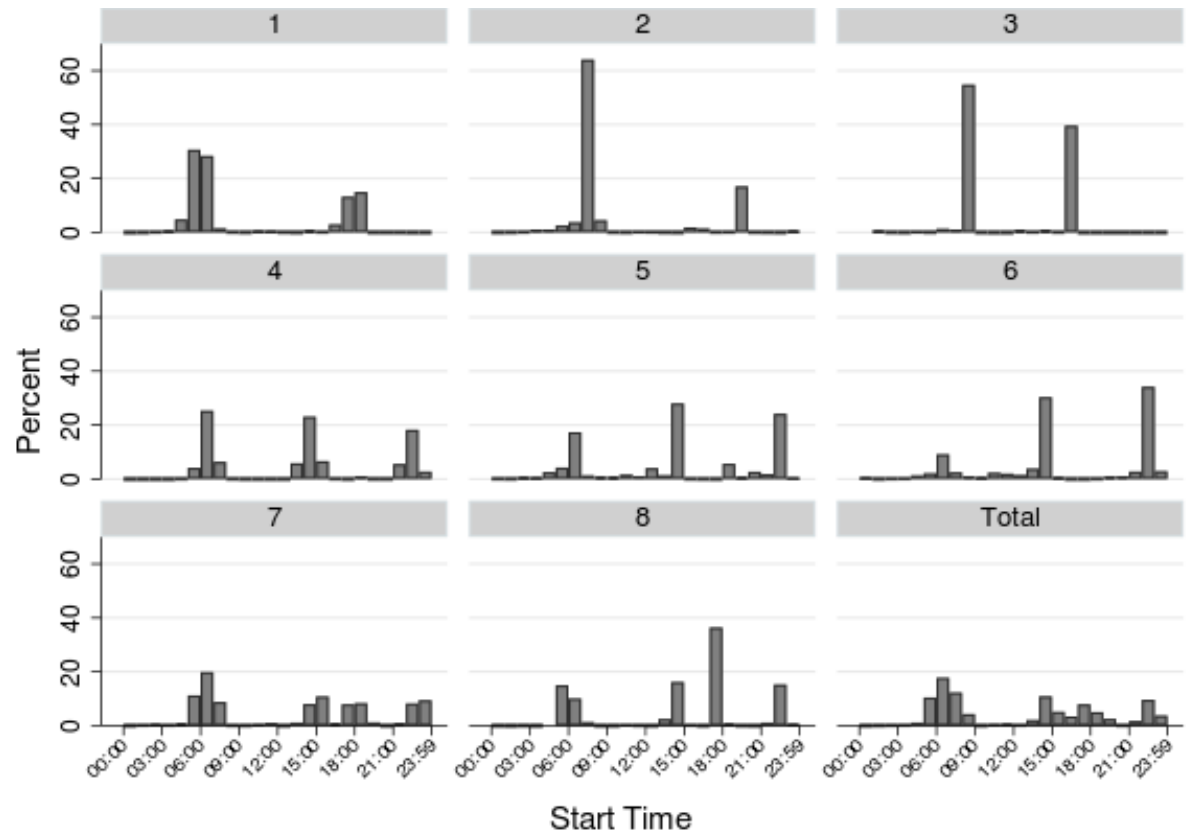

Figure 1. Distribution of shift start times by plant location in the American Manufacturing Cohort (AMC), eight plant subcohort 2003-2013, USA. start times, which corresponds to a worker arriving early or late for a regularly scheduled shift.

There was high variability in night work and rotation exposure. Figure 2 presents the distribution of recent night work among those person-months with at least one night shift. Only $12 \%$ of person-months included no recent night work (ie, non-night work reference group), and the average percentage of recent night work was $37 \%$. Over their entire recorded work history, $88 \%$ of workers worked at least one night shift.

Figure 3 presents the distribution of recent rotational work. $94.5 \%$ of person-months included at least one rotation in the previous year. The majority of workers $(98.7 \%)$ experienced at least one rotation in their recorded work history and the average percentage of recent rotational work was $16 \%$. As seen in figure 4, night work and rotational work were not correlated $(\mathrm{R}=0.06)$. While there were a number of person-months that had both rotation and night work, there were also person-months that were uncorrelated such as the permanent night workers who had no rotations, and the workers who switched frequently from early morning to afternoon day shifts, but never to night shifts.

Table 2 presents results for HR for hypertension and each of the two exposures in three different models: a base model, a more fully adjusted model, and a model that also adjusts for imputed BMI and smoking as a sensitivity analysis. In the base model, the HR were elevated for recent night work, though the exposure-response was non-monotonic, (test for linear trend $\mathrm{P}=0.32$ ). In comparison, the exposure-response relationship for recent rotational work was monotonic (linear trend test $\mathrm{P}=0.05$ ). In the adjusted models, work- ers with relatively little exposure to night work (those with $>0-5 \%$ night work) experienced a doubling in the risk for hypertension [HR 2.30 (95\% confidence interval (CI) 1.06-4.99)] and the risk continued to rise with increasing night work. Those with more than $95 \%$ night shifts had the highest risk of incident hypertension [HR 3.50 (95\% CI 1.21-10.1)]. Recent rotational work was also associated with a linear trend of increasing incident hypertension risk in the adjusted models $(\mathrm{P}=0.01)$; those with $>30 \%$ rotational shifts per month had 3.44 times the risk (95\% CI 1.54-7.69). CI became wider but HR were similar when imputed BMI and smoking status were adjusted for.

Table 3 presents HR for combinations of recent night and rotational shifts and hypertension. Compared to non-night workers, hazards were increased among workers with any recent night work. Among workers who were mostly non-night work with infrequent rotations, the HR for hypertension was 2.18 (95\% CI 0.97-4.87) compared with non-night workers. Workers with mostly night work and frequent rotational exposure were at the highest risk [HR 4.00 (95\% CI 1.69-9.52)]. When BMI and smoking status were treated as confounders, HR were slightly elevated with wider confidence intervals.

In the second sensitivity analysis, we implemented two alternate classifications of recent night work: (i) any night shifts versus none and (ii) number of months working any night shifts. An increased rate of hypertension was seen when night work was defined in either of these alternate classifications (table 4).

In our third sensitivity analysis, workers with $<150$ shifts per year were excluded; 2813 person-months were dropped leaving 2216 subjects and 201 hypertension 


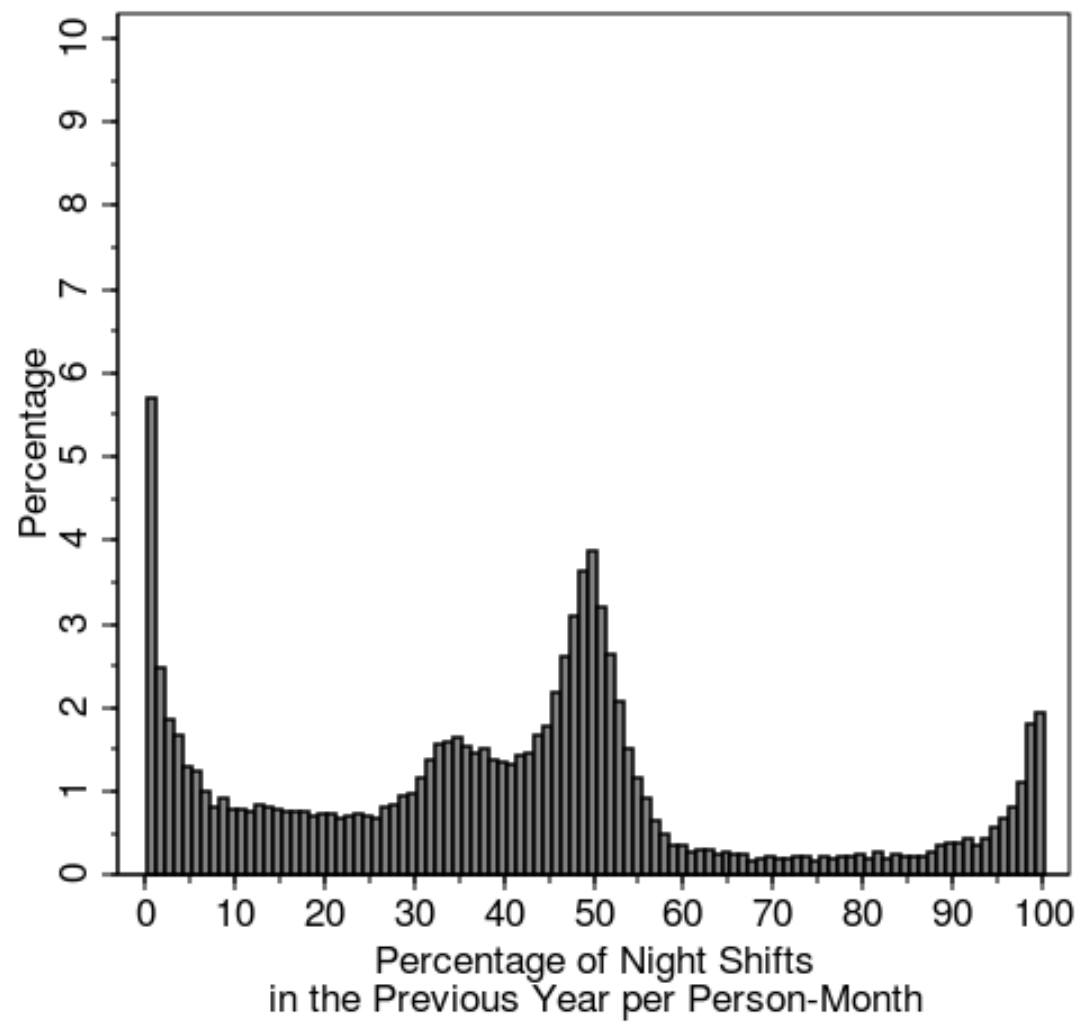

Among the $87 \%$ of Person-Months with Any Night Work $N=55,844$

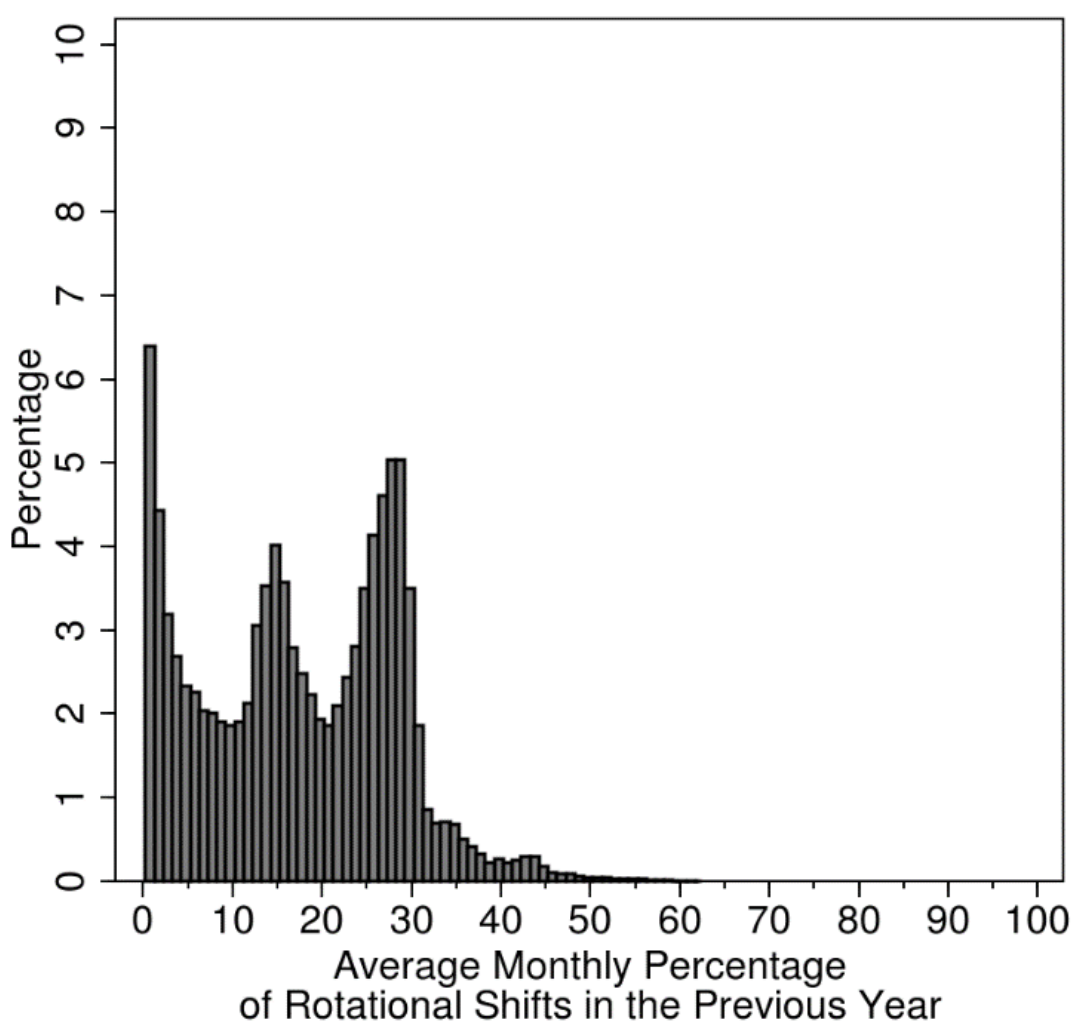

Figure 2. Distribution of person-months with night work in the previous year; restricted to months with $\geq 1$ nightshiftin the previousyear, in the American Manufacturing Cohort, eight plant sub-cohort 2003-2013, USA

Figure 3. Distribution of person-months with rotational work in the previousyear; restricted to months with $\geq 1$ rotation in the previousyear, inthe American Manufacturing Cohort(AMC), eight plant sub-cohort 2003-2013, USA 


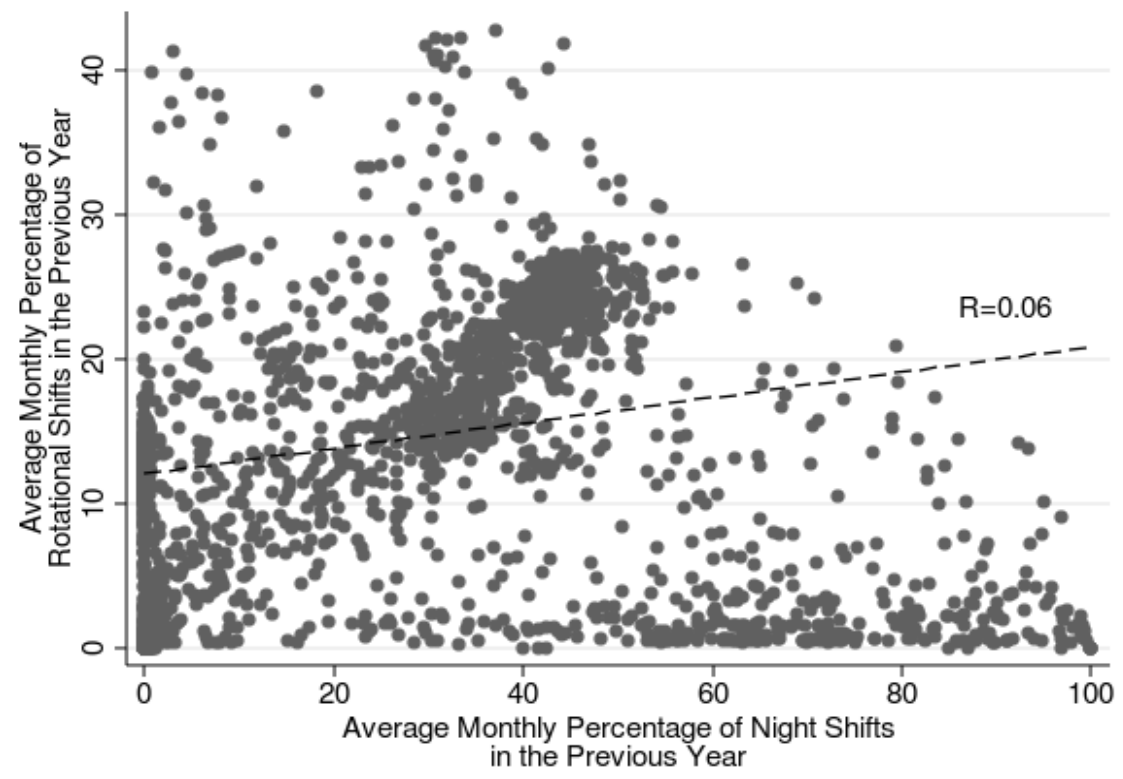

Figure 4. Scatter plot of average monthly percentage of nightand rotational workin the firstyear of follow-up ( $\mathrm{N}=2151)$, in the American Manufacturing Cohort (AMC), eight plant sub-cohort 2003-2013,USA.

Table 2. Hazard ratios (HR) for incident hypertension and recent exposure to night and rotational work. All models have age set as the time-scale and are stratified on sex and location. [BMI=body mass index; $\mathrm{Cl}=$ confidence interval.]

\begin{tabular}{|c|c|c|c|c|c|c|c|c|c|c|c|}
\hline \multirow[t]{2}{*}{ Exposure metric } & \multirow{2}{*}{$\begin{array}{l}\text { Cases } \\
\mathrm{N}\end{array}$} & \multirow{2}{*}{$\begin{array}{l}\text { Person- } \\
\text { months } \\
\text { HR }\end{array}$} & \multicolumn{3}{|c|}{ Base models ${ }^{a}$} & \multicolumn{3}{|c|}{ Adjusted models ${ }^{b}$} & \multicolumn{3}{|c|}{ Adjusted models ${ }^{\mathrm{C}}$} \\
\hline & & & $\mathrm{HR}$ & $95 \% \mathrm{Cl}$ & $\begin{array}{l}\text { P-value for } \\
\text { trend }\end{array}$ & $\mathrm{HR}$ & $95 \% \mathrm{Cl}$ & $\begin{array}{l}\text { P-value for } \\
\text { trend }\end{array}$ & $H R$ & $95 \% \mathrm{Cl}$ & $\begin{array}{l}\text { P-value for } \\
\text { trend }\end{array}$ \\
\hline \multicolumn{12}{|c|}{$\begin{array}{l}\text { Average monthly night shifts in the } \\
\text { previous year (\%) }\end{array}$} \\
\hline 0 & 26 & 7127 & 1.00 & & 0.32 & 1.00 & & 0.07 & 1.00 & & 0.08 \\
\hline$>0-5$ & 34 & 7720 & 2.30 & $1.09-4.86$ & & 2.30 & $1.06-4.99$ & & 2.47 & $1.12-5.44$ & \\
\hline$>5-50$ & 98 & 31336 & 2.26 & $1.08-4.71$ & & 2.29 & $1.02-5.20$ & & 2.40 & $1.04-5.55$ & \\
\hline$>50-95$ & 42 & 13928 & 2.56 & $1.17-5.59$ & & 3.28 & $1.38-7.78$ & & 3.21 & $1.32-7.80$ & \\
\hline$>95-100$ & 15 & 3905 & 2.33 & $0.94-5.80$ & & 3.50 & $1.21-10.1$ & & 3.71 & $1.24-11.09$ & \\
\hline \multicolumn{12}{|c|}{$\begin{array}{l}\text { Average monthly of rotational shifts } \\
\text { in the previous year (\%) }\end{array}$} \\
\hline $0-<1$ & 23 & 6426 & 1.00 & & 0.05 & 1.00 & & 0.01 & 1.00 & & 0.01 \\
\hline $1-10$ & 48 & 14346 & 1.33 & $0.75-2.34$ & & 1.76 & $0.93-3.33$ & & 1.88 & $0.97-3.67$ & \\
\hline$>10-20$ & 59 & 16725 & 1.42 & $0.77-2.64$ & & 1.70 & $0.82-3.50$ & & 1.76 & $0.83-3.77$ & \\
\hline$>20-30$ & 61 & 21022 & 1.52 & $0.85-2.71$ & & 2.30 & $1.11-4.75$ & & 2.30 & $1.09-4.89$ & \\
\hline$>30$ & 24 & 5497 & 2.06 & $1.08-3.96$ & & 3.44 & $1.54-7.69$ & & 3.59 & $1.56-8.23$ & \\
\hline
\end{tabular}

a Base models are not adjusted for confounders set.

${ }^{\mathrm{b}}$ Adjusted for job grade, race, annual health status, calendar year, and the model respective history of night or rotational work (exposure prior to the previous year).

${ }^{\mathrm{c}}$ As above and additionally controlled for BMl and smoking status in a multiple imputed model (M=60).

Table 3. Hazard ratios (HR) for incident hypertension and combinations of recent exposure to night and rotational work. All models have age set as the time-scale and are stratified on sex and location. [BMI=body mass index; $\mathrm{Cl}=$ confidence interval.]

\begin{tabular}{|c|c|c|c|c|c|c|c|c|}
\hline \multirow[t]{2}{*}{ Exposure metric } & \multirow{2}{*}{$\begin{array}{c}\text { Cases } \\
\mathrm{N}\end{array}$} & \multirow{2}{*}{$\begin{array}{c}\text { Person- } \\
\text { months } \\
\text { HR }\end{array}$} & \multicolumn{2}{|c|}{ Base models ${ }^{a}$} & \multicolumn{2}{|c|}{ Adjusted models ${ }^{b}$} & \multicolumn{2}{|c|}{ Adjusted models ${ }^{c}$} \\
\hline & & & $\mathrm{HR}$ & $95 \% \mathrm{Cl}$ & $\mathrm{HR}$ & $95 \% \mathrm{Cl}$ & $\mathrm{HR}$ & $95 \% \mathrm{Cl}$ \\
\hline \multicolumn{9}{|c|}{$\begin{array}{l}\text { Categorical combinations of average monthly percent- } \\
\text { age of night and rotational shifts in previous year }{ }^{d}\end{array}$} \\
\hline Non-night work & 26 & 7127 & 1.00 & & 1.00 & & 1.00 & \\
\hline Mostly non-night work \& infrequent rotations & 37 & 10636 & 2.12 & $0.98-4.56$ & 2.18 & $0.97-4.87$ & 2.40 & $1.06-5.43$ \\
\hline Mostly non-night work \& frequent rotations & 94 & 28412 & 2.35 & $1.15-4.81$ & 2.39 & $1.10-5.20$ & 2.56 & $1.15-5.69$ \\
\hline Mostly night work \& infrequent rotations & 23 & 6376 & 2.14 & $0.90-5.09$ & 2.52 & $0.97-6.50$ & 2.66 & $1.01-7.03$ \\
\hline Mostly night work \& frequent rotations & 35 & 11465 & 2.85 & $1.29-6.27$ & 4.00 & $1.69-9.52$ & 3.99 & $1.64-9.68$ \\
\hline
\end{tabular}

a Base models are not adjusted for confounders set.

${ }^{b}$ Adjusted for job grade, race, annual health status, calendar year, and the model respective history of night or rotational work (exposure prior to the previous year). ${ }^{\mathrm{C}}$ As above and additionally controlled for BMI and smoking status in a multiple imputed model ( $\left.\mathrm{M}=60\right)$.

d Mostly non-night work is defined as $>0 \%$ but $<50 \%$ of shifts in the previous year were night shifts. Mostly night work is defined as $\geq 50 \%$ shifts in the previous year were night shifts. Infrequent rotations are defined as $<10 \%$ of shifts in the previous year were rotational shifts. Frequent rotations are defined as $\geq 10 \%$ shifts in the previous year were rotational shifts. 
Table 4. Hazard ratios (HR) for incident hypertension and exposure to recent night work defined using two alternative definitions. All models have age set as the time-scale and are stratified on sex and location. [Cl=confidence interval.]

\begin{tabular}{|c|c|c|c|c|c|c|c|c|}
\hline \multirow[t]{2}{*}{ Exposure metric } & \multirow{2}{*}{$\begin{array}{l}\text { Cases } \\
\mathrm{N}\end{array}$} & \multirow{2}{*}{$\begin{array}{c}\text { Person-months } \\
\text { HR }\end{array}$} & \multicolumn{3}{|c|}{ Base models ${ }^{a}$} & \multicolumn{3}{|c|}{ Adjusted models ${ }^{b}$} \\
\hline & & & HR & $95 \% \mathrm{Cl}$ & $\begin{array}{l}\text { P-value for } \\
\text { trend }\end{array}$ & HR & $95 \% \mathrm{Cl}$ & $\begin{array}{l}\text { P-value for } \\
\text { trend }\end{array}$ \\
\hline \multicolumn{9}{|c|}{ Night shift in the previous year } \\
\hline Non-night work only & 26 & 7101 & 1.00 & & & 1.00 & & \\
\hline Any night shifts & 189 & 56700 & 2.32 & $1.15-4.69$ & & 2.27 & $1.08-4.80$ & \\
\hline \multicolumn{9}{|c|}{ Any night shifts in the previous year (months) } \\
\hline Non-night work only & 26 & 7101 & 1.00 & & 0.49 & 1.00 & & 0.30 \\
\hline $1-4$ & 30 & 7617 & 2.19 & $1.03-4.68$ & & 2.12 & $0.96-4.66$ & \\
\hline $5-9$ & 44 & 10173 & 2.85 & $1.31-6.20$ & & 2.47 & $1.08-5.64$ & \\
\hline $10-11$ & 43 & 10411 & 3.24 & $1.49-7.03$ & & 2.89 & $1.25-6.68$ & \\
\hline 12 & 72 & 28499 & 1.90 & $0.90-4.01$ & & 2.10 & $0.92-4.80$ & \\
\hline
\end{tabular}

a Base models are not adjusted for confounders set.

${ }^{\mathrm{b}}$ Adjusted for job grade, race, annual health status, calendar year, and history of night work (exposure prior to the previous year)

cases. The results were approximately the same but the CI were larger (results not shown). Finally, in the fourth sensitivity analysis, results based on the IARC definition of night work (a night shift is a shift with $\geq 3$ hours between 00:00-05:00 hours) (5) and the Scandinavian definition ( 3 hours between 23:00-06:00 hours) $(16,17)$ were 98\% concordant and almost identical (results not shown).

\section{Discussion}

Our findings support the hypothesis that recent night and rotational work are associated with an elevated risk of hypertension. The highest rates of hypertension were identified for those with $95-100 \%$ night work, workers who would normally be considered "permanent night workers". This suggests that permanent night workers are experiencing circadian rhythm disruption even though their work schedules are not rotating. This may be due to the social "jet-lag" that night workers experience, as they may "rotate" back to a day schedule on their days off.

Furthermore, we observed elevated HR for all combinations of night and rotational work compared to non-night workers. In particular, the HR was 4-fold for workers with mostly night work and frequent rotations compared with non-night workers. Even those workers with mostly non-night work and infrequent rotations had a 2-fold rate of hypertension.

These estimated risks of hypertension are higher than in previous research. However, we focused on a shorter and more proximate window of exposure (previous 12 months). Most other studies examined shift work in windows $2-5,5-10,10-20$, and $>20$ years prior $(4,37-40)$. Other studies do not specify the exposure period at all $(2,41,42)$. If the most biologically relevant window of exposure for development of hypertension is a year, then we would expect our study to report higher risks than others. Additionally, these studies may have estimated lower risk due to binary definitions of shift work such as ever/current versus never night work $(40,43-47)$

Our study has several limitations. First, our reference category in the models examining the combinations of night and rotational work, combined permanent nonnight workers with workers who may rotate between non-night shifts (ie, morning and afternoon shifts). If there is increased risk of hypertension associated with rotating between non-night shifts, we would have underestimated the impact of rotation on hypertension in the combination model due to the heterogenous reference group. Second, the rotational work metric identifies a switch to a different shift schedule but is indifferent to the severity of a rotation. For example, our metric captures switches from a shift that starts at 15:00 hours to one that starts at 09:00 hours; however, both shifts are generally considered day work and switching between them may have little effect on a worker's circadian rhythms. Furthermore, our metric does not distinguish between forward and backward rotations or the speed/ frequency of rotations which may have differential adverse effects on the circadian system $(7,48,49)$.

Third, hypertension was identified using ICD-9 codes from insurance claims records which reduces, but does not eliminate, outcome misclassification. Although we surely missed some cases, Tessier-Sherman et al (22) examined the validity of claims data in identifying hypertension cases among the insured employees from which this study population was derived. They found the medical service claims to be highly specific $(86 \%)$ while the sensitivity was $43 \%$ indicating this study population may have under-ascertainment of cases (22). Poor sensitivity of an outcome will result in statistical power issues but will not bias the point estimate (50).

Finally, this study may have residual confounding, as we lacked information on personal lifestyle factors such 
as exercise habits, eating patterns, and chronobiologic preference (ie, diurnal preference) (51). Additionally, we were unable to adjust for occupational exposures such as fine particulate matter or noise, which may bias the reported HR $(18,52,53)$. There may also be residual confounding by underlying health status, whereby healthier workers may select into or acquire more shift work exposure than more susceptible workers who may avoid night or rotational shifts (54). In a different cohort of workers, between $20-30 \%$ of shift workers switch to day work schedules within 2-3 years and cite health reasons for switching which suggests that the healthy worker survivor effect may cause downward bias in estimated associations with night work $(55,56)$. While we restricted to workers hired after the start of follow-up, which avoids a form of selection bias, the mean age at baseline was 37 years old and we have no information regarding night or rotational work at prior employment. Moreover, this population of light-metal manufacturers may not be generalizable to other populations as they were part of a highly unionized workforce with excellent access to healthcare.

Despite these limitations, this study is the first longitudinal study using time-registry data to assess the impact of both night and rotational work on incident hypertension risk. This study benefits from longitudinal follow-up and the objective assessment of working hours which does not rely on subject recall and represents actual work time, as opposed to assigned work time. Additionally, this population of aluminum workers are often employed in standardized manufacturing work teams that operate 24 hours a day. Therefore, the reference group of non-night workers are generally performing the same tasks as the night workers and our reference groups are more directly comparable than other shift worker populations. The elevated hazard ratios were robust to multiple sensitivity analyses.

This research supports the hypothesis that recent night and rotational work is associated with an elevated risk of hypertension. Furthermore, this research suggests hypertension risk rises and remains elevated with increasing exposure to night work compared to nonnight work.

\section{Acknowledgments}

We would like to thank Sally Picciotto, Liza Lutzker, Erika Tribett, S. Katherine Hammond, and Elizabeth Noth for their support in this research.

\section{Funding sources}

This study was supported by the National Institutes of Health, Institute of Aging (R01-AG026291), the Centers for Disease Control and Prevention, National Institute of Occupational Safety and Health (R01 OH009939 and 5 T42 OH 8429-13).

This work was presented at the Shift Work \& Disease Session at the $26^{\text {th }}$ Annual EPICOH Meeting, Edinburgh, Scotland, 28-31 August 2017 and at the Shiftwork and Working Time session at the $32^{\text {nd }}$ Triannual International Congress on Occupational Health in Dublin, Ireland 29 April - 4 May 2018.

Note on National Institute of Aging data sharing: As an alternative to providing a de-identified data set to the public domain, we allow access for the purpose of re-analyses or appropriate "follow-on" analyses to any qualified investigator willing to sign a contractual covenant with the host institution limiting the use of data without direct PHI/PII identifiers, in accordance to HIPAA regulations, and with a 15-day manuscript review for compliance purposes. For access to the data, interested parties can contact the study PI, Dr. Mark Cullen, at mrcullen@stanford.edu.

\section{Conflicts of interest}

Dr Mark Cullen has received salary support from Alcoa, Inc. (Pittsburgh, Pennsylvania) through contracts with Stanford University (Stanford, California). The other authors report no conflicts of interest.

\section{References}

1. Manohar S, Thongprayoon C, Cheungpasitporn W, Mao MA, Herrmann SM. Associations of rotational shift work and night shift status with hypertension: a systematic review and meta-analysis. J Hypertens 2017 Oct;35(10):1929-37. https://doi.org/10.1097/HJH.0000000000001442.

2. Rotenberg L, Silva-Costa A, Vasconcellos-Silva PR, Griep RH. Work schedule and self-reported hypertension - the potential beneficial role of on-shift naps for night workers. Chronobiol Int 2016;33(6):697-705. https://doi.org/10.3109 /07420528.2016.1167721.

3. Lu K, Chen J, Wang L, Wang C, Ding R, Wu S et al. Association of sleep duration, sleep quality and shiftwork schedule in relation to hypertension prevalence in chinese adult males: A cross-sectional survey. Int J Environ Res Public Health 2017 Feb;14(2):pii: E210. https://doi. org/10.3390/ijerph14020210.

4. Yeom JH, Sim CS, Lee J, Yun SH, Park SJ, Yoo CI et al. Effect of shift work on hypertension: cross sectional study. Ann Occup Environ Med 2017 Apr;29(11):11. https://doi. org/10.1186/s40557-017-0166-Z.

5. Straif K, Baan R, Grosse Y, Secretan B, Ghissassi F, Bouvard V. IARC Monographs on the Evaulation of Carcinogenic Risks to Humans. 2007. 
6. Agervold M. Shiftwork--a critical review. Scand J Psychol 1976;17(3):181-8. https://doi.org/10.1111/j.1467-9450.1976. tb00229.x.

7. Stevens RG, Hansen J, Costa G, Haus E, Kauppinen T, Aronson KJ et al. Considerations of circadian impact for defining 'shift work' in cancer studies: IARC Working Group Report. Occup Environ Med 2011 Feb;68(2):154-62. https://doi.org/10.1136/oem.2009.053512.

8. United States Bureau of Labor. Occupational Outlook Handbook: 2004-2005. Jist Publishing; 2004.

9. Scheiermann C, Kunisaki Y, Frenette PS. Circadian control of the immune system. Nat Rev Immunol 2013 Mar;13(3):190-8. https://doi.org/10.1038/nri3386.

10. Curtis AM, Bellet MM, Sassone-Corsi P, O’Neill LA. Circadian clock proteins and immunity. Immunity 2014 Feb;40(2):178-86. https://doi.org/10.1016/j. immuni.2014.02.002.

11. Castanon-Cervantes O, Wu M, Ehlen JC, Paul K, Gamble KL, Johnson RL et al. Dysregulation of inflammatory responses by chronic circadian disruption. J Immunol 2010 Nov;185(10):5796-805. https://doi.org/10.4049/ jimmunol.1001026.

12. Bambra CL, Whitehead MM, Sowden AJ, Akers J, Petticrew MP. Shifting schedules: the health effects of reorganizing shift work. Am J Prev Med 2008 May;34(5):427-34. https:// doi.org/10.1016/j.amepre.2007.12.023.

13. Morris CJ, Purvis TE, Mistretta J, Hu K, Scheer FA. Circadian Misalignment Increases C-Reactive Protein and Blood Pressure in Chronic Shift Workers. J Biol Rhythms 2017 Apr;32(2):154-64. https://doi. org/10.1177/0748730417697537.

14. Ohlander J, Keskin MC, Stork J, Radon K. Shift work and hypertension: prevalence and analysis of disease pathways in a German car manufacturing company. Am J Ind Med 2015 May;58(5):549-60. https://doi.org/10.1002/ ajim. 22437 .

15. Noth EM, Dixon-Ernst C, Liu S, Cantley L, Tessier-Sherman B, Eisen EA et al. Development of a job-exposure matrix for exposure to total and fine particulate matter in the aluminum industry. J Expo Sci Environ Epidemiol. Nature Publishing Group; 2013;24(1):89-99.

16. Härmä M, Ropponen A, Hakola T, Koskinen A, Vanttola $\mathrm{P}$, Puttonen $\mathrm{S}$ et al. Developing register-based measures for assessment of working time patterns for epidemiologic studies. Scand J Work Environ Health 2015 May;41(3):26879. https://doi.org/10.5271/sjweh.3492.

17. Garde AH, Hansen J, Kolstad HA, Larsen AD, Pedersen J, Petersen JD et al. Payroll data based description of working hours in the Danish regions. Chronobiol Int 2018 Jun;35(6):795-800. https://doi.org/10.1080/07420528.2018 .1466797 .

18. Brown DM, Petersen M, Costello S, Noth EM, Hammond K, Cullen M et al. Occupational Exposure to PM2.5 and Incidence of Ischemic Heart Disease: Longitudinal Targeted Minimum Loss-based Estimation. Epidemiology 2015 Nov;26(6):80614. https://doi.org/10.1097/EDE.0000000000000329.
19. Costello S, Neophytou AM, Brown DM, Noth EM, Hammond SK, Cullen MR et al. Incident Ischemic Heart Disease After Long-Term Occupational Exposure to Fine Particulate Matter: Accounting for 2 Forms of Survivor Bias. Am J Epidemiol 2016 May;183(9):861-8. https://doi. org/10.1093/aje/kwv218.

20. Tessier-Sherman B, Galusha D, Cantley LF, Cullen MR, Rabinowitz PM, Neitzel RL. Occupational noise exposure and risk of hypertension in an industrial workforce. Am J Ind Med 2017 Dec;60(12):1031-8. https://doi.org/10.1002/ ajim. 22775 .

21. Cullen MR, Vegso S, Cantley L, Galusha D, Rabinowitz $\mathrm{P}$, Taiwo $\mathrm{O}$ et al. Use of medical insurance claims data for occupational health research. J Occup Environ Med 2006 Oct;48(10):1054-61. https://doi.org/10.1097/01. jom.0000241049.23093.a4.

22. Tessier-Sherman B, Galusha D, Taiwo OA, Cantley L, Slade $\mathrm{MD}$, Kirsche SR et al. Further validation that claims data are a useful tool for epidemiologic research on hypertension. BMC Public Health 2013 Jan;13(1):51. https://doi. org/10.1186/1471-2458-13-51

23. LLC P. Prescribers' Digital Reference [Internet]. 2018 [cited 2018 Sep 16]. Available from: http://www.pdr.net/.

24. Clougherty JE, Eisen EA, Slade MD, Kawachi I, Cullen MR Workplace status and risk of hypertension among hourly and salaried aluminum manufacturing employees. Soc Sci Med 2009 Jan;68(2):304-13. https://doi.org/10.1016/j. socscimed.2008.10.014.

25. Centers for Disease Control. Defining Adult Overweight and Obesity [Internet]. Overweight \& Obesity. [cited 2018 Jul 3]. Available from: https://www.cdc.gov/obesity/adult/defining. html.

26. Hamad R, Modrek S, Kubo J, Goldstein BA, Cullen MR. Using "big data" to capture overall health status: properties and predictive value of a claims-based health risk score. PLoS One 2015 May;10(5):e0126054. https://doi. org/10.1371/journal.pone.0126054.

27. Neophytou AM, Costello S, Brown DM, Picciotto S, Noth EM, Hammond SK et al. Marginal structural models in occupational epidemiology: application in a study of ischemic heart disease incidence and PM2.5 in the US aluminum industry. Am J Epidemiol 2014 Sep;180(6):60815. https://doi.org/10.1093/aje/kwu175.

28. Cleves M, Gould WW, Marchenko YV. An Introduction to Survival Analysis Using Stata. 3rd ed. College Station, TX: StataCorp LP; 2016.

29. Harrel FE. Regression Modeling Strategies: With Applications to Linear Model, Logistic Regression, and Survival Analysis. Springer. New York; 2001.

30. Pepłońska B, Burdelak W, Krysicka J, Bukowska A, Marcinkiewicz A, Sobala W et al. Night shift work and modifiable lifestyle factors. Int J Occup Med Environ Health 2014 Oct;27(5):693-706. https://doi.org/10.2478/s13382014-0298-0.

31. Kim MJ, Son KH, Park HY, Choi DJ, Yoon CH, Lee HY 
et al. Association between shift work and obesity among female nurses: Korean Nurses' Survey. BMC Public Health 2013 Dec;13(1):1204. https://doi.org/10.1186/1471-245813-1204.

32. Nea FM, Kearney J, Livingstone MB, Pourshahidi LK, Corish CA. Dietary and lifestyle habits and the associated health risks in shift workers. Nutr Res Rev 2015 Dec;28(2):143-66. https://doi.org/10.1017/ S095442241500013X.

33. van Amelsvoort LG, Jansen NW, Kant I. Smoking among shift workers: more than a confounding factor. Chronobiol Int 2006;23(6):1105-13. https://doi. org/10.1080/07420520601089539.

34. Azur MJ, Stuart EA, Frangakis C, Leaf PJ. Multiple imputation by chained equations: what is it and how does it work? Int J Methods Psychiatr Res 2011 Mar;20(1):40-9. https://doi.org/10.1002/mpr.329.

35. Royston P, White I. Multiple Imputation by Chained Equations (MICE): implementation in Stata. J Stat Softw 2011;45(4). https://doi.org/10.18637/jss.v045.i04.

36. Rubin DB. Multiple Imputation for Nonresponse in Surveys. New York: John Wiley \& Sons; 1987.

37. Chen JD, Lin YC, Hsiao ST. Obesity and high blood pressure of 12-hour night shift female clean-room workers. Chronobiol Int 2010 Jan;27(2):334-44. https://doi. org/10.3109/07420520903502242.

38. Burdelak W, Bukowska A, Krysicka J, Pepłońska B. Night work and health status of nurses and midwives. crosssectional study. Med Pr 2012;63(5):517-29.

39. Violanti JM, Owens SL, Fekedulegn D, Ma CC, Charles LE, Andrew ME. An Exploration of Shift Work, Fatigue, and Gender Among Police Officers: the BCOPS Study. Workplace Health Saf 2018 Nov;66(11):530-7. https://doi. org/10.1177/2165079918754586.

40. Morikawa $Y$, Nakagawa $H$, Miura K, Ishizaki M, Tabata M, Nishijo $\mathrm{M}$ et al. Relationship between shift work and onset of hypertension in a cohort of manual workers. Scand J Work Environ Health 1999 Apr;25(2):100-4. https://doi. org/10.5271/sjweh.411.

41. Ceide ME, Pandey A, Olafiranye O, Pandey AK, Donat M, Brown CD et al. Linking sleep duration to night shift-work and hypertension. In: Sleep. Amer Acad Sleep Medicine; 2012. p. A203-A203.

42. Sfreddo C, Fuchs SC, Merlo AR, Fuchs FD. Shift work is not associated with high blood pressure or prevalence of hypertension. PLoS One 2010 Dec;5(12):e15250. https://doi. org/10.1371/journal.pone.0015250.

43. Sakata K, Suwazono Y, Harada H, Okubo Y, Kobayashi E, Nogawa K. The relationship between shift work and the onset of hypertension in male Japanese workers. J Occup Environ Med 2003 Sep;45(9):1002-6. https://doi. org/10.1097/01.jom.0000085893.98441.96.

44. Oishi M, Suwazono Y, Sakata K, Okubo Y, Harada H, Kobayashi E et al. A longitudinal study on the relationship between shift work and the progression of hypertension in male Japanese workers. J Hypertens 2005 Dec;23(12):2173 8. https://doi.org/10.1097/01.hjh.0000189870.55914.b3.

45. Ellingsen T, Bener A, Gehani AA. Study of shift work and risk of coronary events. J R Soc Promot Health 2007 Nov;127(6):265-7. https:/doi. org/10.1177/1466424007083702.

46. Suwazono Y, Dochi M, Sakata K, Okubo Y, Oishi M, Tanaka $\mathrm{K}$ et al. Shift work is a risk factor for increased blood pressure in Japanese men: a 14-year historical cohort study. Hypertension 2008 Sep;52(3):581-6. https://doi. org/10.1161/HYPERTENSIONAHA.108.114553.

47. Hublin C, Partinen M, Koskenvuo K, Silventoinen K, Koskenvuo M, Kaprio J. Shift-work and cardiovascular disease: a population-based 22-year follow-up study. Eur J Epidemiol 2010 May;25(5):315-23. https://doi.org/10.1007/ s10654-010-9439-3.

48. Kantermann T, Duboutay F, Haubruge D, Hampton S, Darling AL, Berry JL et al. The direction of shift-work rotation impacts metabolic risk independent of chronotype and social jetlag--an exploratory pilot study. Chronobiol Int 2014 Dec;31(10):1139-45. https://doi.org/10.3109/0742052 8.2014 .957295 .

49. van Amelsvoort LG, Jansen NW, Swaen GM, van den Brandt PA, Kant I. Direction of shift rotation among three-shift workers in relation to psychological health and work-family conflict. Scand J Work Environ Health 2004 Apr;30(2):149-56. https://doi.org/10.5271/sjweh.772.

50. Rothman KJ, Greenland S, Lash TL. Modern epidemiology. Lippincott Williams \& Wilkins; 2008.

51. Costa G. Shift work and health: current problems and preventive actions. Saf Health Work 2010 Dec;1(2):112-23. https://doi.org/10.5491/SHAW.2010.1.2.112.

52. Stokholm ZA, Bonde JP, Christensen KL, Hansen ÅM, Kolstad HA. Occupational noise exposure and the risk of hypertension. Epidemiology 2013 Jan;24(1):135-42. https://doi.org/10.1097/EDE.0b013e31826b7f76.

53. Costello S, Brown DM, Noth EM, Cantley L, Slade MD, Tessier-Sherman B et al. Incident ischemic heart disease and recent occupational exposure to particulate matter in an aluminum cohort. J Expo Sci Environ Epidemiol. Nature Publishing Group; 2014;24(1):82-8.

54. Brown DM, Picciotto S, Costello S, Neophytou AM, Izano MA, Ferguson JM et al. The Healthy Worker Survivor Effect: Target Parameters and Target Populations. Curr Environ Heal Reports. Curr Environ Health Rep 2017;4(3):364-72.

55. Harrington JM. Shift work and health--a critical review of the literature on working hours. Ann Acad Med Singapore 1994 Sep;23(5):699-705.

56. Kuhn G. Circadian rhythm, shift work, and emergency medicine. Ann Emerg Med 2001 Jan;37(1):88-98. https:// doi.org/10.1067/mem.2001.111571.

Received for publication: 24 July 2018 